\title{
The INGVterremoti channel on YouTube
}

\author{
Alessandro Amato ${ }^{\star}$, Luca Arcoraci, Emanuele Casarotti, Raffaele Di Stefano \\ and the INGVterremoti team ${ }^{\dagger}$
}

Istituto Nazionale di Geofisica e Vulcanologia, Rome, Italy

\author{
Article history \\ Received January 3, 2012; accepted February 8, 2012. \\ Subject classification: \\ Seismology, Educational, History of Science, Public Issues, Earthquakes, Seismic awareness, Seismic hazard.
}

\begin{abstract}
In February 2010, we launched an experimental scientific video channel on YouTube (http://www.youtube.com/ingvterremoti), to improve our communication strategy for earthquake risk and preparedness. The main goals of this initiative were to inform people of the ongoing seismic activity in Italy and around the World, to communicate the results of scientific research in seismology, and to increase the knowledge of seismic hazard of the people. To date, after almost two years from the start, we have published 52 original videos on YouTube, through the collaboration of many researchers at the Istituto Nazionale di Geofisica e Vulcanologia (INGV). The videos are organized into eight play lists: (i) earthquakes in Italy; (ii) earthquakes worldwide; (iii) the 2009 L'Aquila, Italy, earthquake; (iv) ongoing seismic activity; (v) tsunami; (vi) earthquake prediction; (vii) seismic hazard; and (viii) May 112011 (when a major earthquake was predicted to hit Rome). To date, the total number of views is over 466,000, with two peaks of more than 20,000/day after the Tohoku, Japan, earthquake (March 2011) and before the presumed prediction of a major earthquake to hit Rome on May 11, 2011. The most popular videos (6) have been viewed more than 20,000 times, with a maximum of over 67,000. We think that this initiative has increased people's knowledge and awareness of seismic risk, although at the moment the outreach is limited only to a specific (but growing) target of citizens. In the future, we will try to improve the technical aspects of our video communication, and we will try to broaden our audience. We have learned that when specific earthquakes occur (or even when there are unfounded predictions about upcoming seismic events) this is when the attention is highest, which represent the best occasions to move forward towards improved risk communication strategies.
\end{abstract}

\section{Introduction}

Seismological and seismic hazard studies have strong social impact. Most of what seismologists accomplish is used in seismic hazard maps and then in seismic risk reduction. In this perspective, one of our main goals as research seismologists is to transfer our knowledge to the relevant authorities and to the general public. Geoethics implies that we will do our best to increase the earthquake awareness and preparedness of society, to face future hazards in the right way.

Civil protection officers benefit from seismological research because seismic hazard maps are used for seismic zonation and for the definition of the correct building codes. In addition, we know that one of the main steps to reduce earthquake risk is to increase the level of knowledge and awareness of the public, including teachers, students, local authorities, civil protection volunteers, and others. For this reason, the Istituto Nazionale di Geofisica e Vulcanologia (INGV) is involved in many educational activities with schools, as well as in information transfer efforts through a variety of tools. These include continuous and detailed information on seismic activity and hazard in Italy through our website (http: / www.ingv.it), through school programs, and more recently through social media, such as Twitter, an iPhone App, and YouTube.

In recent years, several universities and research institutes have started to release scientific information through social media, including YouTube, and more in general, scientific videos [Grime 2011, Woolley 2011]. In geophysics, the American Geophysical Union is expanding science communication through videos [AGU 2011] and scientific blogs, while new ways of science video communications are offered today (see for instance SymphonyofScience.com). In addition, social media are becoming a powerful tool to involve people in geophysical sciences and earthquake monitoring [Allen 2012].

In this contribution, we will describe briefly the INGV YouTube channel (youtube.com/INGVterremoti), with the focus on the history of this initiative and with discussion of its social impact.

\section{Motivation and history of the INGV YouTube channel}

The need for the better improving and communicating of information on seismic activity in Italy and on seismic hazard reduction increased significantly after the 2009 L'Aquila earthquake. Although the seismic hazard of the 
area was well known even before the earthquake (see www.ingv.it/terremoti/pericolosita-sismica/ and www. protezionecivile.gov.it/jcms/it/classificazione.wp), many people living there were not aware of the risk and were not prepared for a strong earthquake. This emphasizes the importance of correct communication to the media and to the people, not only during a crisis (such as an ongoing seismic sequence), but also in 'quiet' times. The main goal of the youtube/INGVterremoti channel is to increase the quantity and quality of the information about ongoing seismic activity and seismic hazard in Italy, and in other regions of the World, with the final goal of increasing the awareness and preparedness of the people.

The birth of the channel youtube/INGVterremoti dates back to February 2010. Since then, 52 videos have been uploaded, with an increasing number of views, that has reached today a total of more than 466,000 . In the first year of activity, we had about 100,000 total channel views, while in the following period (March-December 2011) the audience increased significantly (by a factor of four). This was mostly due to strong events that raised the attention on earthquakes, but also to a general increase in our audience. To give a better idea of what this number means, we can compare it with the YouTube channel of the U.S. Geological Survey (USGS) (http:/ / www.youtube.com/usgs), which started in 2006 and which has a total number of videos almost five times greater than the INGV YouTube channel (261). At the time we write, the total number of views for the two channels is $\sim 264,000$ versus $\sim 467,000$ for the USGS and INGV channels, respectively. The USGS channel contains videos on a broader variety of topics, from climate to earthquakes, from volcanoes to floods, and of animals, and much more.

The number of views of the INGV YouTube channel has increased over time, with two obvious main peaks in the history of the views (Figure 1a). These two peaks (both over 20,000 per day) correspond to the Tohoku, Japan, earthquake on March 11, 2011, and the presumed Rome earthquake prediction for May 11, 2011. In the first case, we prepared a quick video from the INGV seismic monitoring room in which the senior seismologist on duty (Franco Mele) explained what had just happened in Japan. The sudden increase in views (more than 30,000 in four days; see Figure 2) showed us the importance of being able to post a new video quickly, when attention is high. Besides the immediate response in terms of number of views, we found that people looking for some rapid information after a specific event can be attracted by the other contents of the channel. In the case of the second peak [see also Nostro et al. 2012, in this volume], the increase was due to the presumed prediction of a strong earthquake to hit Rome on May 11, 2011. In this case, we prepared and published a video explaining the story of this fake prediction one month before the predicted date of the earthquake. The video was viewed by several thousand people in the month before the earthquake, with an average rate of more than 1,000 views per day (Figure 3), thus reaching more than 30,000 views by May 8 ; then it increased to several thousand/day on May 9, 10 and 11 $(7,186,17,458$, and 7,216 , respectively), and rapidly became our most viewed movie, with more than 67,000 clicks. Even several days afterwards, the video was still being viewed 20-30 times per day (Figure 3).

Apart from these two peaks described above, Figure $1 \mathrm{~b}$ shows the level of views from July 1 to December 31, 2011, a period without any really strong seismic events. The current rate ranges between 250 to 1,000 views per day. More recently, we registered another 'double' peak after two moderate earthquakes in northern Italy in January 2012 (Figure 1a), with more than 6,400 views on the day of the M 5.4 Parma earthquake (January 27, 2012).

\section{Contents and numbers}

The videos that we have produced can be basically grouped into four main categories: 1. Periodic descriptions of ongoing seismic activity in Italy; 2. Reports of large earthquakes worldwide; 3. Specific scientific seismological topics; and 4. Radio and television interviews with seismologists. In addition, some videos have been added as preferred for their relevance to earthquake science or science in general, with links to other channels. The videos are at present organized into eight play lists: (i) earthquakes in Italy; (ii) earthquakes worldwide; (iii) the 2009 L'Aquila earthquake; (iv) ongoing seismic activity; (v) tsunami; (vi) earthquake prediction; (vii) seismic hazard; (viii) May 11, 2011 (the major earthquake predicted to hit Rome). The play lists are allowed to have some partial redundancy.

These productions were all made 'in house' (except for one video on tsunamis that was previously commissioned to a professional company and then used for the INGV YouTube channel), with cheap hardware and software, and internal resources used for the movie making, postproduction and editing. The main cost of the channel consists of the salaries of the people involved, who dedicate a limited part of their working research time to film making. The participation of many researchers (about 30) who have been willing to make themselves available to explain their research or to comment on some specific ongoing event is considered very important.

In general, the number of appreciations (the so-called 'I like') are much larger than the 'I don't like'. Figure 4 shows the relative comparison of the two, with 990 positive and 26 negative votes, which correspond to $97.4 \%$ and $2.6 \%$ of the total, respectively. Moreover, we consider the number of comments posted by users on the INGV YouTube channel or on specific videos as an indication of 


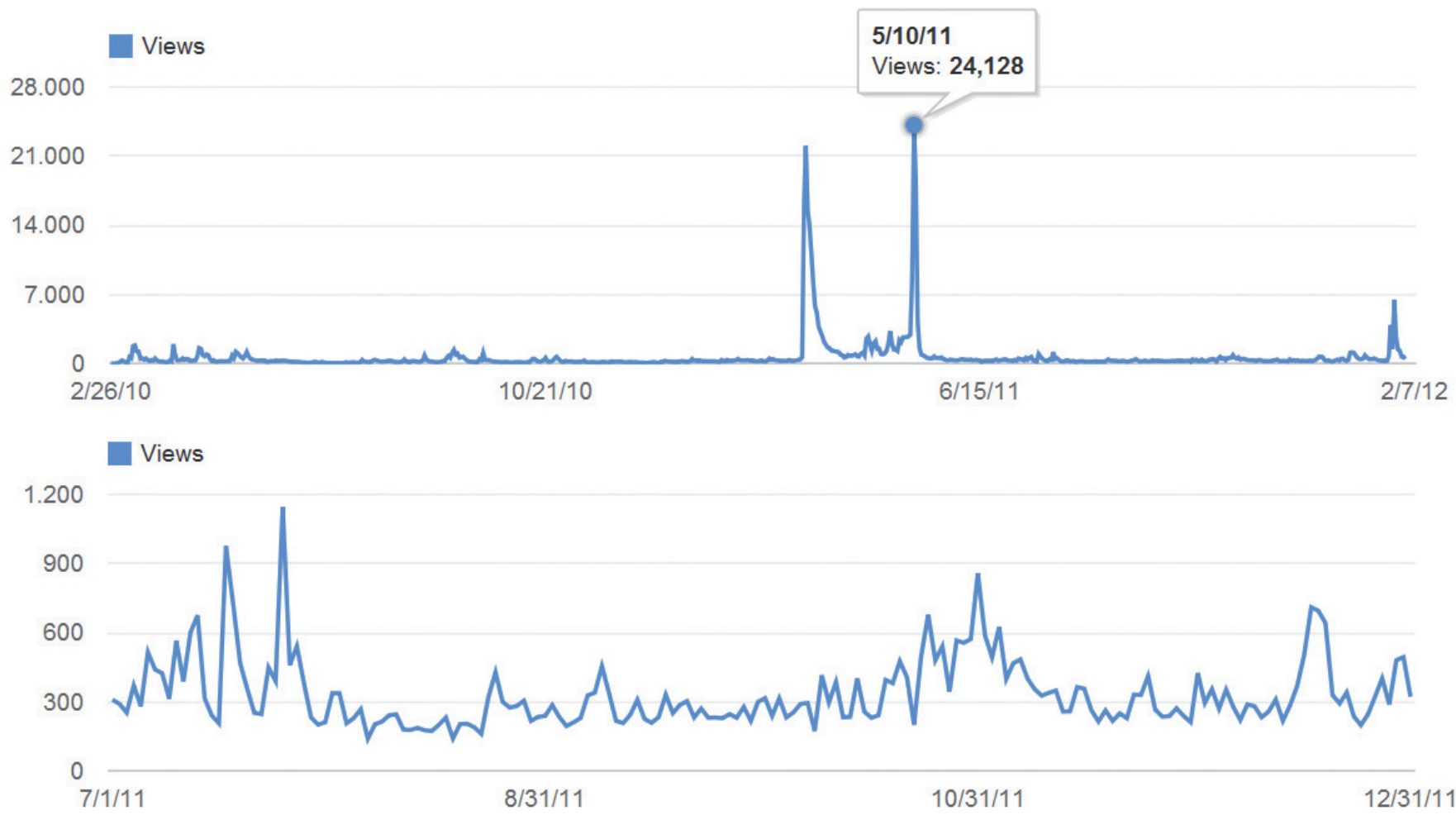

Figure 1. Top: History of daily INGV YouTube channel views from February 2010 to the beginning of February 2012. The two main peaks corresponding to the Tohoku, Japan, earthquake on March 11, 2011, and the Rome presumed earthquake prediction on May 11, 2011. The third double peak at the end of January 2012 was due to some moderate shocks felt in northern Italy. Bottom: Detail for the number of INGV YouTube channel views for JulyDecember 2011. Even without strong events, the daily number of views remains relatively high (around 300-400), with some peaks around 1,000.

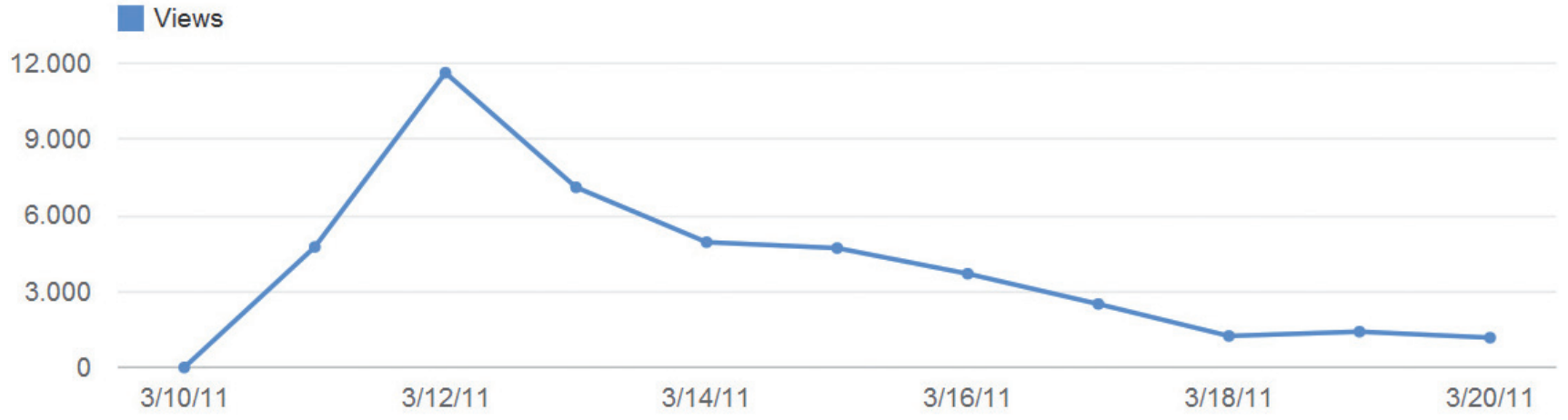

Figure 2. History of daily views for the Tohoku, Japan, video prepared on the afternoon of March 11, 2011, which was viewed by more than 30,000 people in the first four days.

\section{Views}

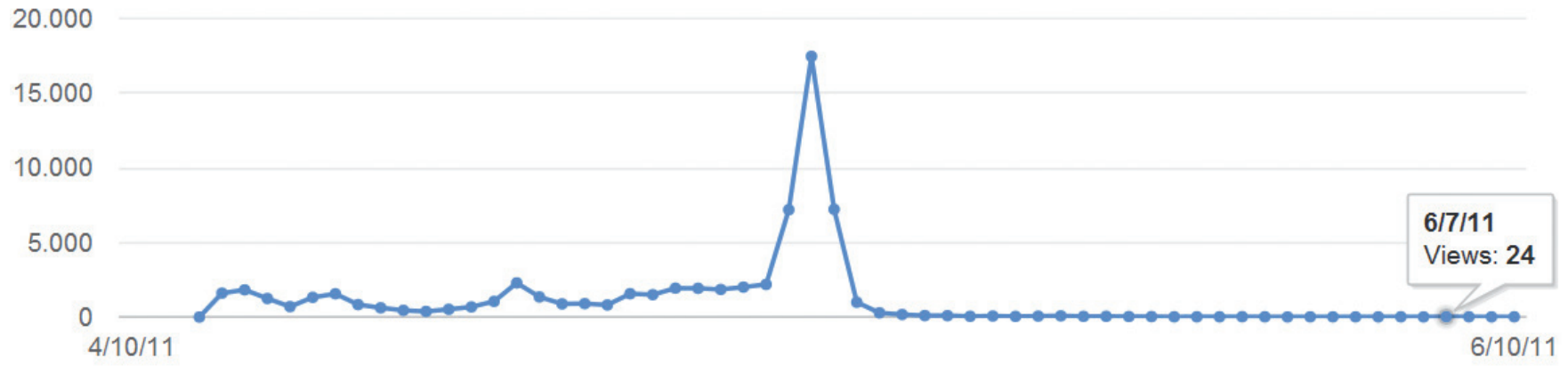

Figure 3. Number of daily views for the video Terremoto a Roma l'11 maggio 2011? (Earthquake in Rome on May 11, 2011?), which scored a total of more than 67,000 views. The peak was reached the day before the prediction (May 10), with about 18,000 views. 


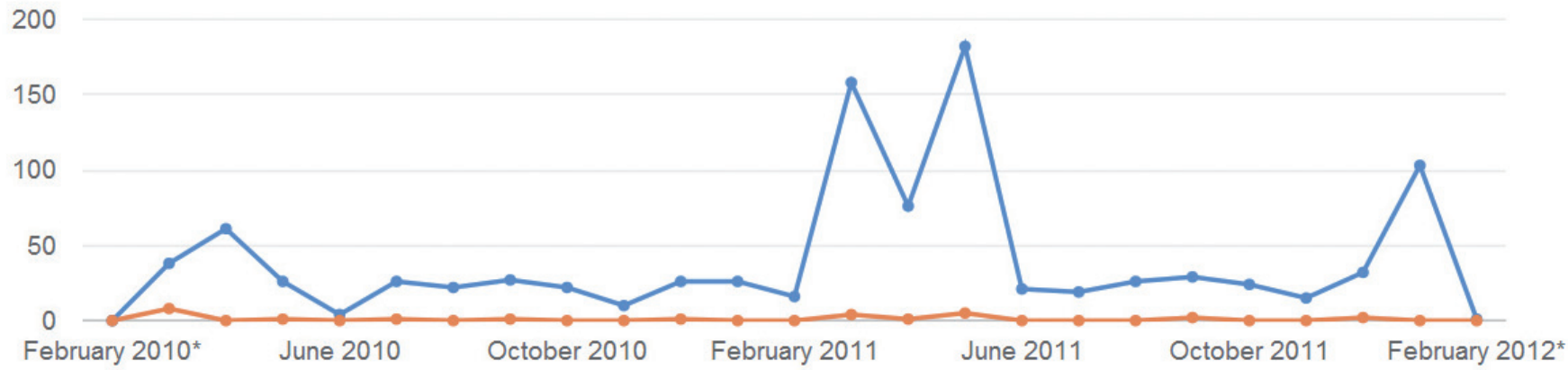

Figure 4. History of the 'I like' (blue) versus 'I don't like' reports per month. The total numbers are 990 vs. 26. Most comments were posted in March and May 2011, and January 2012.

Comments

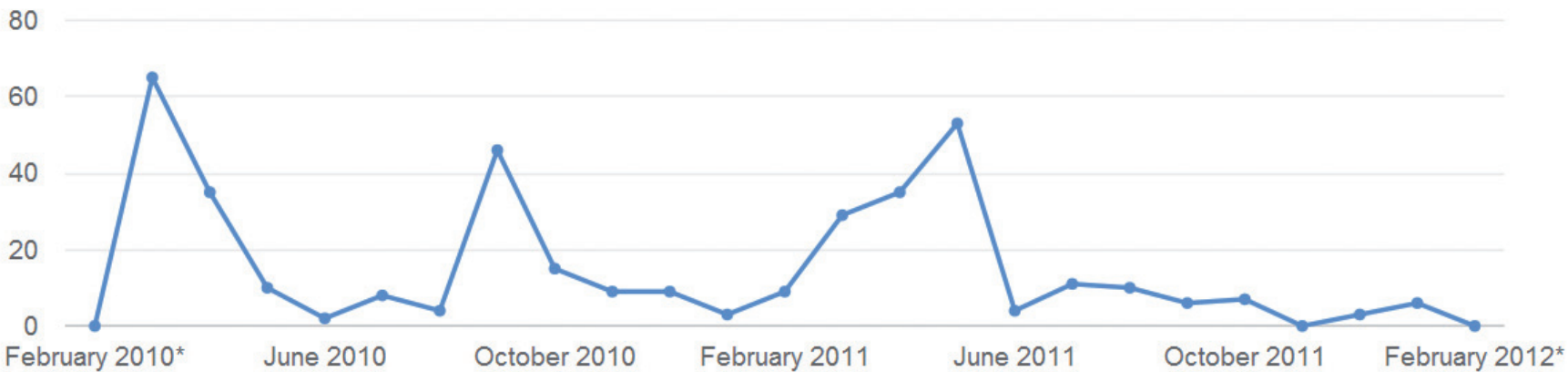

Figure 5. Number of monthly comments on the INGV YouTube channel from the opening to date ${ }^{\star}$. The peaks generally coincide with the publication of videos on relevant events. The first peak followed the publication of a video on the L'Aquila earthquake, with a reconstruction of its presumed prediction.

the interest and involvement of the public (Figure 5). To date, we have had 379 comments concerning the channel and specific videos. Most of the comments have been positive (acknowledgements), with many containing requests for additional information; a few have been critical. Most of these latter refer to the impossibility for us to predict earthquakes, which is often compared with reference to some people who claim to be able to make such predictions. We are not able to answer to all of the questions, requests and complaints posted on the channel, but we try to do this as much as possible, when the questions are fair and motivated by scientific interest. We believe that the interactions with the public are an essential part of our work, and for this reason we are planning to increase this side, not only through the INGV YouTube channel, but also through a specific blog site and other social media (ingvterremoti.wordpress.com).

Another measure of the channel activity can be obtained by looking at the video sharing in the community. Figure 6 shows the monthly number of sharings, with values around zero in the first year and a strong increase in the period March-May 2011, after the Japan earthquake and the Rome earthquake prediction. It is meaningful that in the following months (June-December 2011) the level of sharing was low, but higher than before, ranging be- tween 10 and 25 shared videos per month, and with a peak of 106 in January 2012.

The number of people registered to the channel (subscribers) has increased relatively constantly over time (Figure 7), reaching 1,721 today, and increasing at about 20-40 per month in the last period, with 42 in December 2011, and then 273 in January 2012 due to the M 4-5 earthquakes in northern Italy. Although our channel is dedicated to the Italian population, and therefore all videos (except one) are in Italian, we also have a significant public abroad, and particularly in USA (about 8,000 views), Spain and Thailand (more than 3,000 each), Brasil, UK, Switzerland, France, Germany (more than 2,000 each). Most of these are related to one specific video on tsunamis, which is dubbed in English and has been seen by more than 34,000 people, and also by Italians living outside Italy.

Some of the most clicked videos obtained their success several weeks or months after their publication. This happened, for instance, for the videos on tsunamis that were posted a few months before the Tohoku disaster of March 11, 2011. Immediately after the earthquake and tsunami struck Japan, many people looked on the internet for videos, images and information on large earthquakes and tsunamis. Our videos were originally prepared after the Sumatra tsunami of 2004, and they were pub- 


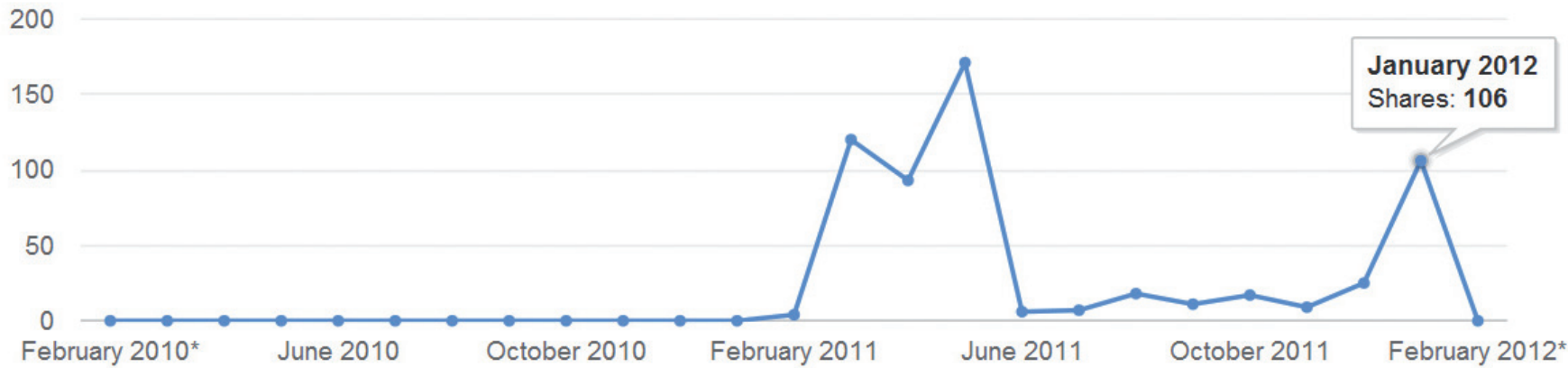

Figure 6. Number of shared videos per month for the INGV YouTube channel from the opening ${ }^{\star}$ to date ${ }^{\star}$. Note that before the March-May 2011 period, the monthly averages were near zero, while in the following months they were around 10-25, with a relevant peak in January 2012 (106 sharings).

\section{Subscribers net change}

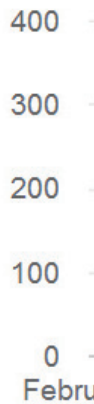

February 2010*

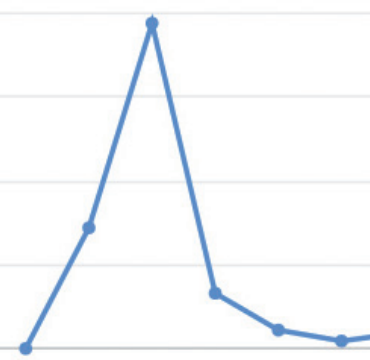

June 2010
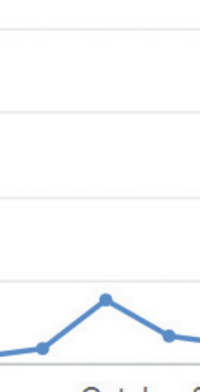

October 2010

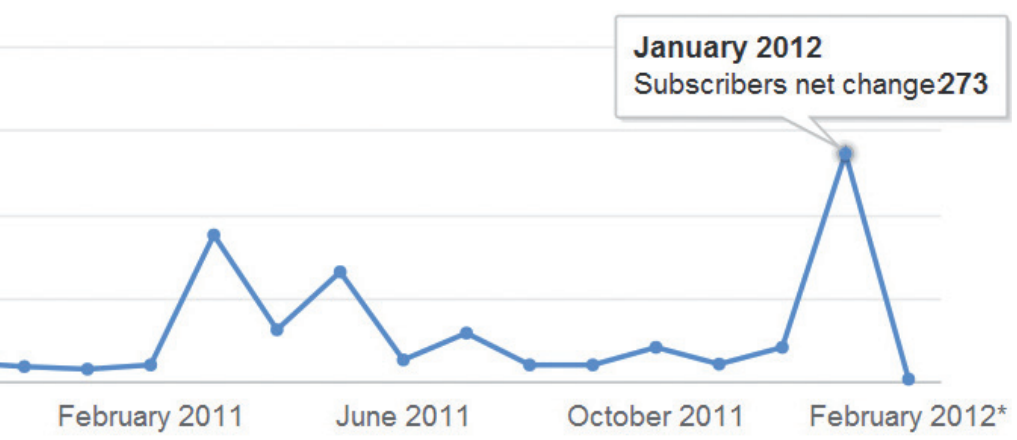

Figure 7. Monthly number of subscribers to the INGV YouTube channel from the opening ${ }^{\star}$ to date ${ }^{\star}$. As well as peaks related to specific events, there is a constant rate of 20-40 new subscribers every month. In January 2012, we had the second highest peak (from the time of the opening of the INGV YouTube channel), with 273 new subscribers.

lished on DVD for schools, and then posted on the INGVterremoti channel in 2010 for a broader audience. After March 2011, they were seen and appreciated by thousands of people, because they explained the origin of tsunamis in a scientific, but simple and effective, way.

The numerous videos produced for the May 11, 2011, fake prediction of an earthquake in Rome deserves a specific mention [see also Nostro et al. 2012, this volume]. We used the INGV YouTube channel to communicate with people who were afraid of, or just curious about, the presumed impending earthquake. Besides the over 3,000 inhabitants of Rome who came to visit the INGV Laboratories in Rome on the day, several tens of thousands of people accessed our information through the INGV YouTube channel. We published 12 movies during that day, starting from 1:00 am on May 11, and finishing at 1:00 am on May 12. We decided to alternate updates from the seismic monitoring room every two hours, each time focusing on a specific aspect of earthquake monitoring (e.g. how we locate earthquakes, how we measure their magnitude, among others), with more general videos on seismic hazard, site effects, active faults, and so on. Besides a large number of views of many of these movies during May 11, most of them were seen several times also in the following days, and some of them are still very popular.

\section{Conclusions}

The INGVterremoti channel on YouTube was inaugurated on February 2010, to increase the level of information about earthquakes in Italy, which represents a basic step for seismic risk reduction. The INGV researchers involved in seismology and seismic hazard studies are aware that this is a very important issue for society, particularly in Italy, where the frequent seismicity, and more importantly high building vulnerability and low preparedness, raise the risk. Over 50 videos have been posted to date, most of which have been produced with 'in-house' resources and non-professional equipment and software. Although this sometimes results in low quality technical content (e.g. audio, lights), we have preferred to focus on the scientific contents rather than spending too much time on the various aspects of film making. However, we are trying to improve our techniques, without losing immediacy or reducing the amount of information that we post. The audience numbers described in this report are encouraging, with more than 466,000 total views, a constant growth rate, and continued growing interest, as is witnessed by the number of shared videos and the number and comments of subscribers. We will continue to use this medium as a tool for informing and increasing awareness of seismic risk of the people. We intend to increase the quality and quan- 
tity of information both on ongoing seismicity and on the hot research topics in earthquake science.

Acknowledgements. We thank all of our colleagues who have participated in the film making, for their dedication of some of their time to the dissemination of scientific knowledge: Andrea Tertulliani, Franco Mele, Massimo Cocco, Carlo Meletti, Daniela Pantosti, Stefano Salvi, Francesca Cinti, Salvatore Mazza, Lauro Chiaraluce, Alberto Michelini, Anthony Lomax, Paolo Marco De Martini, Paola Vannoli, Valerio De Rubeis, Patrizia Tosi, Paola Sbarra, Diego Sorrentino, Licia Faenza, Claudio Chiarabba, Calvino Gasparini, Paola Montone, Antonio Meloni, Graziano Ferrari, Lucia Margheriti, Luigi Cucci, Alberto Frepoli, Elisa Trasatti, Nicola D’Agostino, Antonio Piersanti, Pio Lucente, Alberto Basili, and Aybige Akinci. We also thank Domenico Sisti for the video on the May 11, 2011, Open Day.

\section{References}

Allen, R.M. (2012). Transforming earthquake detection?, Science, 335 (6066), 297-298; doi:10.1126/science.1214650.

American Geophysical Union (AGU) (2011). The S-factor, http:/ / agusfactor.org/sfactor_blog/.

Grime, J. (2011). How YouTube is popularising science, The Guardian (Science blog), http: / / www.guardian.co. $\mathrm{uk} /$ science/blog/2011/may/17/youtube-popularisingscience (last accessed, February 3, 2012).

Nostro, C., A. Amato, G. Cultrera, G. Margheriti, G. Selvaggi, L. Arcoraci, E. Casarotti, R. Di Stefano and the May 11 Team (2012). Turning the rumor of the May 11, 2011, earthquake prediction in Rome, Italy, into an information day on earthquake hazard, Annals of Geophysics, 55 (3), 413-420; doi:10.4401/ag-5559.

Woolley, S. (2011). Youtube: a Science Communication World at your finger tips, University of Melbourne, Scientific Scribbles, Permalink: http:/ / blogs.unimelb.edu. $\mathrm{au} /$ sciencecommunication/2011/05/19/youtube-ascience-communication-world-at-your-finger-tips/.

\footnotetext{
† The youtube INGVterremoti team includes:

Concetta Nostro, Corrado Castellano, Lucia Margheriti,

Giovanna Cultrera, Maurizio Pignone and Giulio Selvaggi.
}

${ }^{\star}$ Corresponding author: Alessandro Amato,

Istituto Nazionale di Geofisica e Vulcanologia, Rome, Italy; email: alessandro.amato@ingv.it.

(C) 2012 by the Istituto Nazionale di Geofisica e Vulcanologia. All rights reserved. 